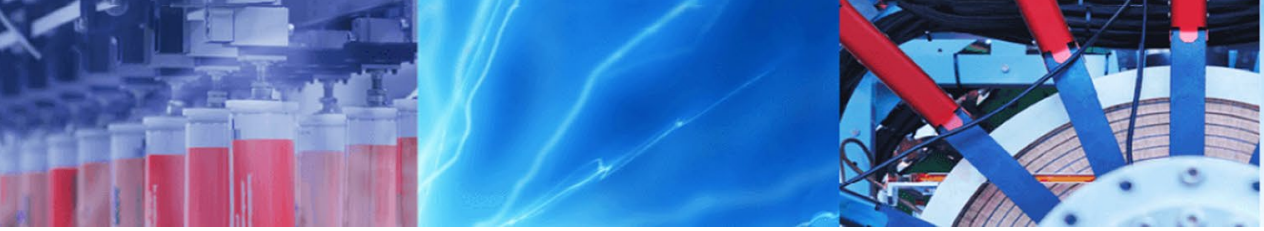

Research Article

\title{
Modeling, attenuation and flow field analysis of diesel engine muffler using fluid structure interaction approach and experimental analysis
}

\author{
P. V. Shinde ${ }^{1} \cdot$ R. G. Desavale ${ }^{2}$-V. R. Patil ${ }^{1}$ P. M. Gawali ${ }^{1,2} \cdot$ S. M. Patil ${ }^{1}$
}

Received: 2 January 2020 / Accepted: 2 April 2020 / Published online: 18 April 2020

(c) Springer Nature Switzerland AG 2020

\begin{abstract}
The acoustic attenuation and acoustic pressure levels of a single-cylinder diesel engine are computed using COMSOL Multiphysics tool to evaluate the performance of the reactive muffler. To increase the travel of exhaust gas, internal modifications in the geometry of the muffler has been done. The experimental analysis shows that the pressure drop for the new developed model is much lesser than that of the existing model for same conditions. CFD approach is employed to investigate the effect of flow velocity and temperature on the acoustic attenuation performances of both muffler models. The experimental and numerical results of transmission loss have been validated. The results of the numerical analysis show close agreement with the experimental results. It is observed that the backpressure of the new developed muffler faces $42 \%$ reduction. Increasing the volume of the muffler with a single perforated baffle plate leads to noise reduction of 5.5\%. The new developed muffler has been used to study the effects of transmission loss, acoustic attenuation analysis and acoustic pressure levels for the low-frequency range.
\end{abstract}

Keywords Perforated baffle plate $\cdot$ Acoustic attenuation $\cdot$ Noise $\cdot$ Acoustic pressure levels

\section{Introduction}

Internal combustion engines serve as one of the main contributors to noise pollution globally [1]; causing partial or permanent hearing impairment under prolonged exposure at very high decibels. A Muffler is used to dampen the engine vibrations and velocity of the exhaust gases resulting in reduction of amount of noise generated by engines. The pulsating flow from each cylinder in exhaust process creates pressure impression in the exhaust system.

Pressure level varies with the engine speed as well as load. At higher speeds and loads, the exhaust manifold pressure is significantly above atmospheric pressure. Internal combustion engines produce acoustic beats due to the combustion process. The noise which is generated due to acoustic beats can be eliminated by the use of silencers or mufflers. Continuous progress has been made in silencer design to reduce the exhaust noise. Mufflers are generally used to diminish the exhaust noise which is a predominant source in vehicle noise [2].

Chen et al. [3] studied the cross flow and straight flow perforated tube silencers. They concluded that the cross flow perforated tube silencers shows increase in transmission loss with increase in the flow of air at most of the frequencies. On the other hand, air flow had less influence on the acoustic attenuation for the straight flow perforated tube silencers. But the straight flow perforated tube silencers shows good results at higher frequencies. Shah et al. [4] studied various models by changing internal geometry. Results obtained show that, by changing volume of the expansion chamber and perforations, silencer shows optimized attenuation and back pressure.

P.V. Shinde, prasadshinde7174@gmail.com; R. G. Desavale, ramdesavale@rediffmail.com; V. R. Patil, vijaypatil872@gmail.com; P. M. Gawali, gawalipm89@gmail.com; S. M. Patil, sushant.rit@gmail.com | ${ }^{1}$ ADCET, Ashta, Maharashtra 416301, India. ${ }^{2}$ Department of Mechanical Engg., RIT, Sakhrale, Uran Islampur, Maharashtra 415414, India. 
Mogal et al. [5] concluded that noise can be reduced effectively by using absorptive material like wool-felt. Middelberg et al. [6] concluded CFD can be fruitfully used to analyze the mean flow as well as acoustic performance of an expansion chamber muffler, with various modifications including baffle plates and extension in inlet and outlet. Parlar et al. [7] concluded axial resonances and transverse propagation modes supported by the muffler at cut of frequency. It is observed that the back pressure increases with increase in volumetric flow rate. Potente and Daniel [8] mentioned that the absorptive muffler offers better noise attenuation and controls noise at both low frequencies and high frequencies. Generally, as the volume of the resonating chamber increases, the resonant frequency reduces. Ying-li et al. [9] proposed segregation of the flow in two parts and integrating them to cancel out each other by intersection of the flows. Numerical simulation and experimentation show better performance in terms of noise reduction, insertion loss and back pressure than the original passive muffler for diesel engine, under different operating conditions. Guhana et al. [10] used a 3D design tools for weight reduction of the exhaust system. Their new system design with exhaust gas temperature, noise level, back pressure and sound quality offers a reduction of volume by 15 percentage and reduction of weight by 2 percentage. The new system is optimized for noise level and pressure drop. Also, the results of experimentation and CFD simulation were validated. Jong et al. [11] proposed numerical model for level differences, transmission loss and insertion loss were proposed and validated. Varieties of schemes are converse to illustrate the effect of impedance at the end of the duct, tailpipe length and the locations of the measurement points, on the noise attenuation. Salamet et al. [12] proposed the time domain analysis for different silencer devices for acoustic attenuation. Broatch [13] presented the 3-D time domain approach for the analysis of acoustic attenuation for single expansion chamber and reversing chamber muffler. Lee et al. [14, 15] presented the pressure drop of concentric silencer with five different patterns using CFD and experiments. Overall compared results agree well with experiments. Xue and Sun [16] offered muffler practice of $U$ shaped corrugated pipes, when used in chamber for noise optimization over the insertion pipe muffler. Experiments were carried out to calculate aerodynamic parameter and reduction in noise. Hence, the noise reduction performance appreciably gets better, exceeding the upper cutoff frequency. Jianbing Gao et al. [17] investigated the particle and gas-phase polycyclic aromatic hydrocarbon (PAH) concentrations of non-road diesel engines. The investigation was carried out for different engine load conditions and showed the effectiveness of the Non-thermal plasma (NTP) technology to reduce PAH emissions.
Jianbing Gao et al. [18] studied the oxidation activity of diesel particulate matter (PM) in the sample collected at different tailpipe positions. The collected samples are presented for temperature until $40 \%$ loss and ages for 40 days in air. The results obtained showed that the oxidation activity restored by aging in air. Jian bing Gao et al. [19] analyzed the energy flow in a turbocharged diesel engine for improving fuel economy and reducing exhaust emissions. The recycled energy by turbocharger was obtained and the potentials of reducing exhaust emissions and fuel consumptions were estimated and effect on the thermal energy was investigated. Yaqiang Xue et al. [20] studied the transmission loss of reactive by non-uniform rational B-splines (NURBS) process. The author employed multipatch technique to parameterize the reactive mufflers. The mathematical modelling of interior 3-D acoustics with (NURBS) and formulation were presented. The Circular, elliptical and conical reactive expansion chamber mufflers are analyzed and the effectiveness of the method is verified. Adrien Mann et al. [21] premeditated the muffler to alter the jet like actions of the flow throughout the baffles. Reduction of noise by $20 \mathrm{dBA}$ with small rounded holes porous approach. The engine output is a boundary condition to simulate the muffler acoustic and aerodynamic performance in LBM. Usama Tohid et al. [22] conducted a parametric study via numerical simulations of a PULSCO vent silencer. Results of Advantex for the selected group of circumstances were weighed against numerical solution. Xue et al. [23] offered muffler practice of $U$ shaped corrugated pipes when used in chamber for noise optimization over the insertion pipe muffler. Experiments were carried out to calculate aerodynamic parameter and reduction in noise. Hence, the noise reduction performance appreciably gets better, exceeding the upper cutoff frequency. Yedeg et al. [24] discussed a technique of material distribution. Mortar-element method was used to control opening of resonator. Numerical results show better performance of mufflers with high transmission loss at wide frequency range. Zhang et al. [25] proposed an innovative opinion for dropping the airflow velocity, which depends upon split-stream rushing method. Proposed muffler shows significant reduction in airflow velocity and back pressure. Bhattacharya et al. $[26,27]$ illustrated that the noise could be reduced sufficiently by means of a well-designed muffler. Reactive muffler was designed and fabricated and the transmission loss of the developed muffler was calculated at $1200 \mathrm{rpm}$. The results were compared with the conventional muffler in term of brake thermal efficiency and brake specific fuel consumptions and drop of pressure was also measured. Shinde et al. [28] elaborates the different types of muffler, along with design and selection criteria.

The objectives of this research are (1) to develop a new model and pressure acoustic approach is used to 
determine acoustic attenuation and acoustic pressure levels. (2) to study effect of flow velocity and temperature on acoustic attenuation performance of both the models using CFD approach. (3) to study the effects of existing model and new developed model on engine performance characteristics. (4) to calculate acoustic attenuation and pressure drop for both the models. The back pressure of the existing model and new developed model were obtained by experimental results. In this research paper, flow field analysis and acoustic pressure levels of the existing and new developed muffler are analyzed and numerical results are compared with experimental one.

It is observed that there is a scope for numerical and experimental study of the reactive muffler for the single cylinder diesel engine for the acoustic pressure and transmission loss analysis. It is noticed that a little work has been carried out for the experimental testing of a muffler on actual test rig. This research work has been presented to study experimental and numerical analysis of actual testing of existing and new developed muffler. With the new developed muffler, significant reduction in noise is obtained with maximum transmission loss. In this model, reduction in back pressure, acoustic attenuation and better specific fuel consumption is attained with good agreement in numerical and experimental results. The numerical simulation was carried out in COMSOL and the developed muffler was tested on $4 \mathrm{hp}$ diesel engine. It shows good response.

This paper is organized as follows. In Sect. 2 Numerical implementations along with modelling is formulated 2 . In Sect. 3, Experimental details are proposed for acoustic attenuation and back pressure. In Sect. 4, Results are given. In Sect. 5 Discussions are given and in Sect. 6 Concluding remarks are elaborated.

\section{Numerical implementation}

Acoustic characteristics can be determined by transmission loss. In this connection, numerical analysis has been performed to obtain the transmission loss of the existing and the new developed muffler by COMSOL. In this analysis, the mean flows of the muffler were not considered. The muffler geometries were modeled using CATIA. The mufflers were meshed with tetrahedral elements. The minimum wavelength of a muffler is $0.250 \mathrm{~m}$. For a sound testing, the mesh size must be less than $1 / 6$ th of the wavelength [7]. Therefore, a mesh size of $0.020 \mathrm{~m}$ has been used in the muffler.

In this analysis, sound pressure, $\mathrm{p}$ is determined with Helmholtz Eq. (1).

Given $\nabla\left(\frac{1}{\rho} \nabla p-q\right)+\frac{k^{2} p}{\rho}=0$

where,

$\mathrm{k}=\frac{2 \pi f}{\mathrm{c}}$ is the wavelength, $\rho$ is the density of the fluid and $c$ is the speed of sound.

$q=$ two pole source terms which means acceleration per unit volume [7].

With this equation, a solution on frequency domain can be found using a parametric solver. Transmission loss of the muffler is determined using Eq. (2) as

$\mathrm{TL}=10 \log \left(\frac{\mathrm{W}_{\text {in }}}{\mathrm{W}_{\text {out }}}\right)$

where $w_{\text {in }}$ and $w_{\text {out }}$ describe acoustic effects on inlet and outlet of the muffler, respectively. The acoustic effects are determined using Eqs. (3) and (4) as

$\mathrm{w}_{\mathrm{in}}=\int \frac{\mathrm{p}_{\mathrm{i}}^{2}}{2 \rho \mathrm{c}} \mathrm{dA}$

$\mathrm{w}_{\text {out }}=\int \frac{\mathrm{p}_{\mathrm{o}}^{2}}{2 \rho c} \mathrm{dA}$

Equations (2), (3) and (4) were specified in the program as a variable and the inlet pressure value $\left(p_{i}\right)$ was taken as 1 bar. The model uses sound hard boundary conditions at the solid boundaries as described in Fig. 4 and in Eq. (5)

$\left(-\frac{\nabla p}{\rho}\right) \cdot n=0$

The 3-D drawings of the geometry are shown in Figs. 1 and 3.

\subsection{Prototype model}

Figure 1 shows the existing muffler model considered in the present study. It is observed that the existing muffler model shows more travel of the exhaust gas. As path of exhaust gas is increased, noise is reduced due to acoustic impedance. To increase the path of exhaust gas, one cup is located on the inner surface of the muffler as shown in Fig. 1. The exhaust gas will enter in the chamber through extended pipe and it is released into the cup. Gas released into the cup strikes the base of the cup and rebounds with some velocity. This ultimately leads to increase of the path of the gas travel. The detailed specifications of the existing model: Length $130 \mathrm{~mm}$, Diameter of expansion chamber $88 \mathrm{~mm}$ which consists of 22 outlets of $5 \mathrm{~mm}$ diameter each (Fig. 2). 


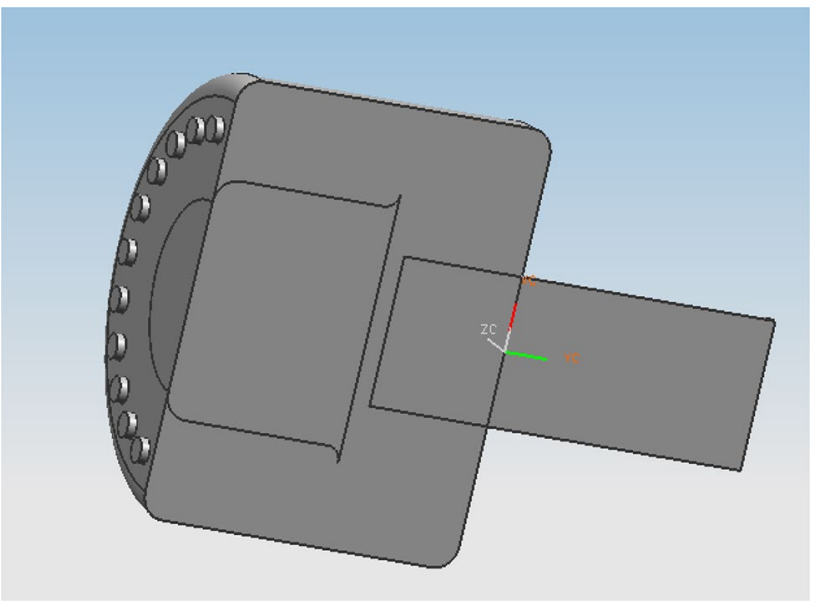

Fig. 1 CAD model of the existing muffler

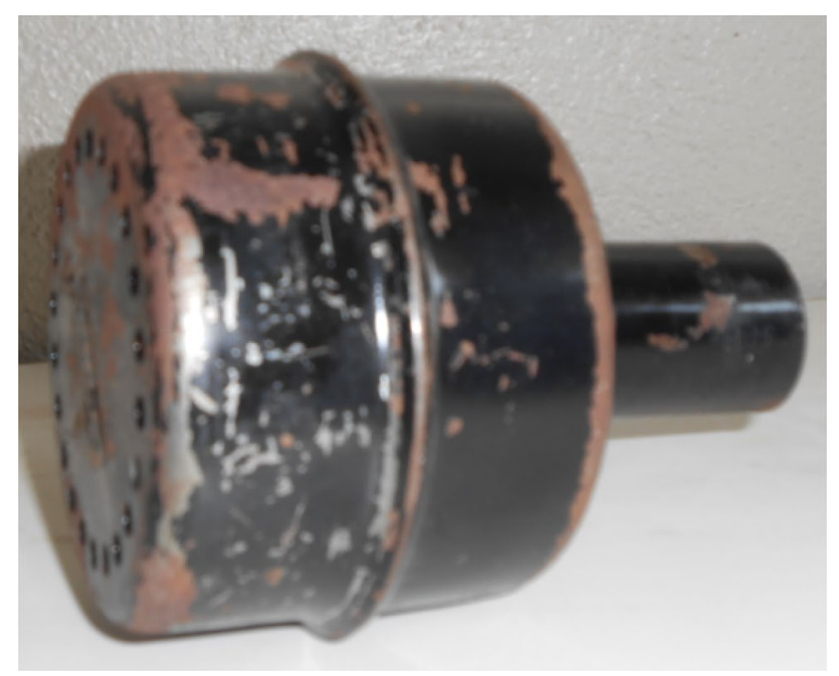

Fig. 2 Prototype of existing muffler

The new developed muffler model is considered as the new model as shown in Fig. 3. In this case, increase in length of travel of the exhaust gas is one of the important parameter for the sound reduction so, the length of the model has been increased. For further reduction of noise, baffle plate has been incorporated in the chamber as shown in Fig. 3. Inside part of the inlet pipe has been

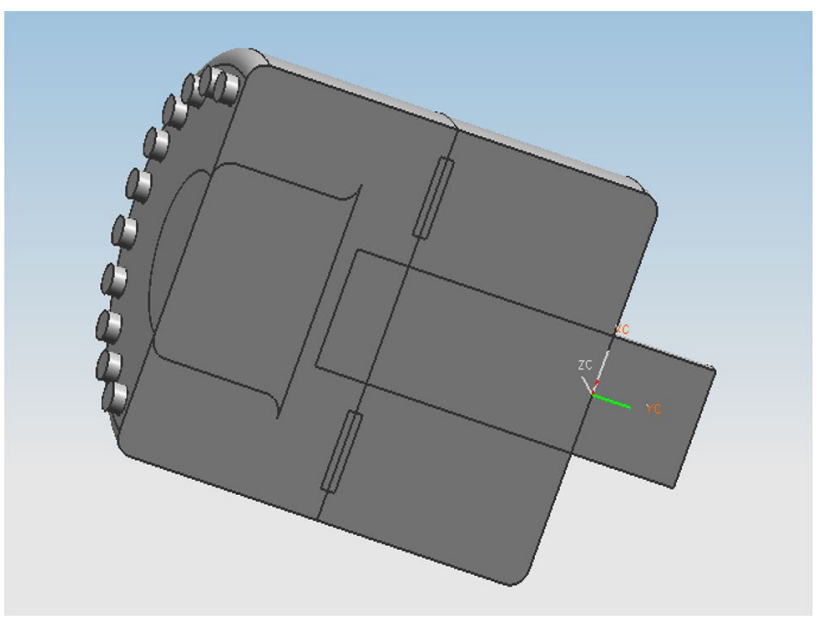

Fig. 3 CAD model of the new developed muffler

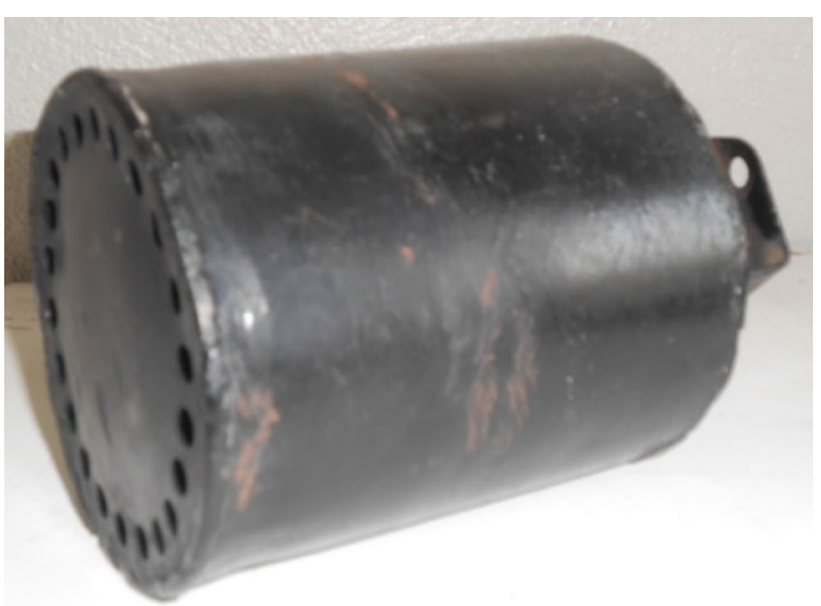

Fig. 4 Prototype of new developed muffler

made perforated while, other structural parts are kept same as that of the existing muffler model. The detailed specifications and dimensions of the new model are: length of $150 \mathrm{~mm}$ and $100 \mathrm{~mm}$ diameter. This model is of single baffle plate, extended inlet pipe with multiple outlets ( 22 Holes) each having diameter of $7 \mathrm{~mm}$. Porosity of extended inlet is 15\% (Fig. 4). 


\subsection{Numerical modelling}

To improve the numerical results pressure acoustic approach, the acoustic module COMSOL is used. Simulation of the muffler has been performed with the help of numerical approach. In the light of the similar design and development, the new muffler has been tested for noise reduction and also to find the transmission loss. To analyze the noise levels, comparison of results of the two mufflers, simulation software package has been used. The various steps carried out to get the acoustic levels are described in the Fig. 5. Transmission loss has been determined directly in the simulation software using the acoustic power at the inlet and outlet of the muffler. The numerical analysis of acoustic attenuation and transmission loss has been carried out in COMSOL. The procedure of numerical simulation is as below,

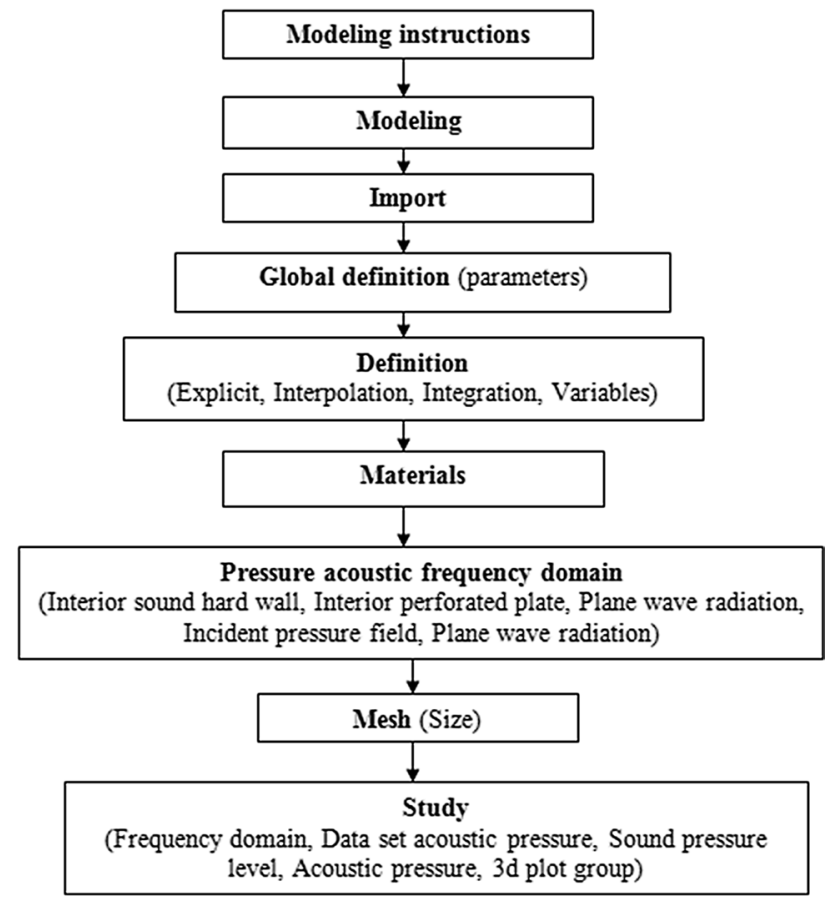

Fig. 5 Numerical modeling-flow chart

\section{Experimental analyses}

Figure 6 shows the experimental setup for transmission loss measurement. It consists of 4-channel Adash 4400 VA4 Pro Ver. 2.21 analyzer and pressure type microphone along with frequency generator has been used for transmission loss measurement. The noise signal generated by frequency generator has been transmitted to the speaker to produce the sound. Generated noise by speaker has been transmitted to the muffler. Sound pressure signals are recorded over a period of time with the microphones which are placed at inlet and outlet of the muffler and these signals have been transformed into frequency domain using FFT analyzer. The results of spectrum are obtained. The computer has processed the data obtained from the analyzer and the transmission loss plots are generated.

Performance characteristics such as sound attenuation and back pressure were studied using actual testing of the engine on the test rig as shown in Fig. 7. The Figs. 1 and 3 show existing model and the new developed model which are used for experimental testing. Experimental test set up consist of $4 \mathrm{hp}$ diesel engine, engine dynamometer, dynamometer controller, $\mathrm{U}$ tube manometer, sound meter etc. The engine is mounted on the test rig chassis. The arrangement of the instruments is as shown in Fig. 7. The details of the specifications of the engine are given in Table 1.

The Carden shaft is used to connect the engine and the dynamometer. A continuous water supply is given to the engine dynamometer to maintain the dynamometer at normal operating temperatures for the duration of the prescribed engine tests.

The sound was measured at a distance of $1 \mathrm{~m}$ from the exhaust pipe and at an angle of $45^{\circ} \pm 5^{\circ}$ to the axis of the exhaust system. The reference axis of the sound meter shall lie in a plane parallel to the ground surface and shall be directed towards the reference point on the exhaust

Fig. 6 Experimental test rig

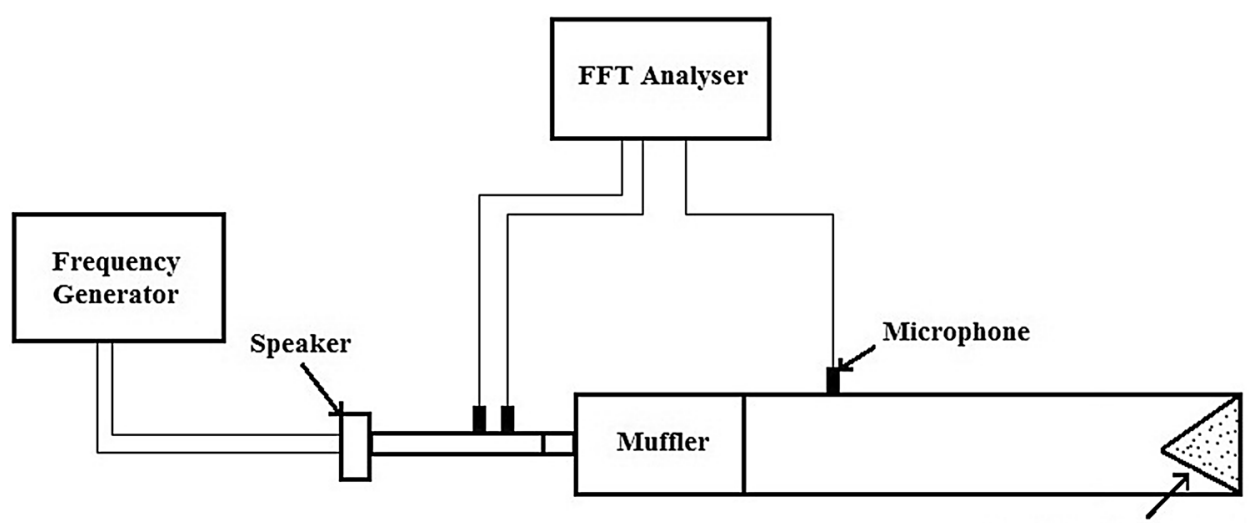

Anechoic Termination 
Table 1 Engine operating conditions

\begin{tabular}{lll}
\hline SR & Particulars & Specifications \\
\hline 1 & No. of cylinder & 1 \\
2 & Rated power & $2.94 \mathrm{~kW}$ \\
3 & Bore diameter & $80 \mathrm{~mm}$ \\
4 & Stroke length & $62 \mathrm{~mm}$ \\
5 & Swept Volume & $311 \mathrm{cc}$ \\
6 & Cooling system & Air cooled \\
7 & Speed range & $1950-2650 \mathrm{rpm}$ \\
\hline
\end{tabular}

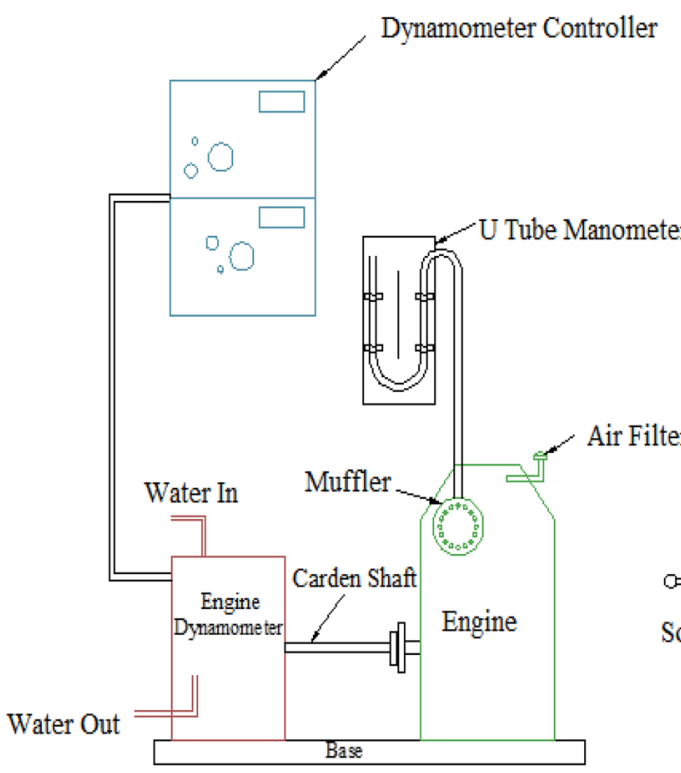

Fig. 7 Experimental test rig for sound measurement

outlet. The back pressure was measured using U-tube manometer which is shown in Fig. 7.

\section{Results}

\subsection{Existing model}

Figure 8 shows the acoustic pressure level results of existing muffler using pressure acoustic approach. In order to examine the effects of exhaust gases strike on the surface perpendicular to the direction of the sound waves, the sound wave applies maximum acoustic pressure on that surface. Considering when exhaust gas is entering the muffler, it does not come across any surface which is perpendicular to the path of sound wave. It is noticed from Fig. 8, that the inlet of the muffler shows less acoustic pressure. The results of the acoustic pressure have been shown in Fig. 8. As per the boundary conditions, the variation of

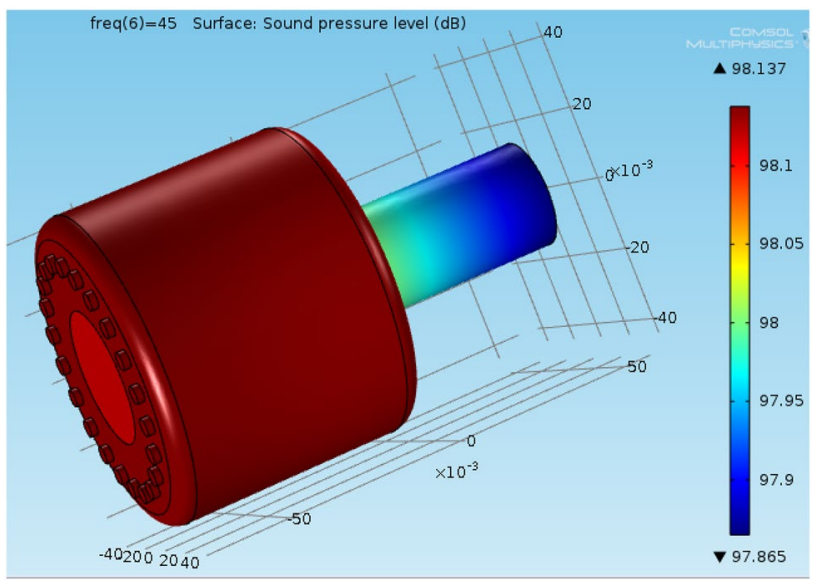

Fig. 8 Acoustic pressure of existing muffler

the color contours in the respective zones indicates the sound pressure levels in respective region.

The numerical analysis of flow field analysis has been done using CFX. The procedure of numerical simulation is given below,

Simulation of the existing muffler has been done with the help of CFX tool [29]. The boundary conditions are set as

\begin{tabular}{lll}
\hline 1 & Inlet (entrance) of muffler & Mass flow rate \\
2 & Outlet (exit) of muffler & Outlet pressure \\
3 & Wall & Stationary, \\
& & adiabatic, and \\
& non slip \\
\hline
\end{tabular}

The contour plot for turbulence kinetic energy and velocity vector are obtained as shown in Figs. 9 and 10 . Simulation result significantly shows that, the abrupt change of the flow velocity inside the existing muffler, particularly near the cup region, increases turbulent kinetic energy and causes additional pressure drop.

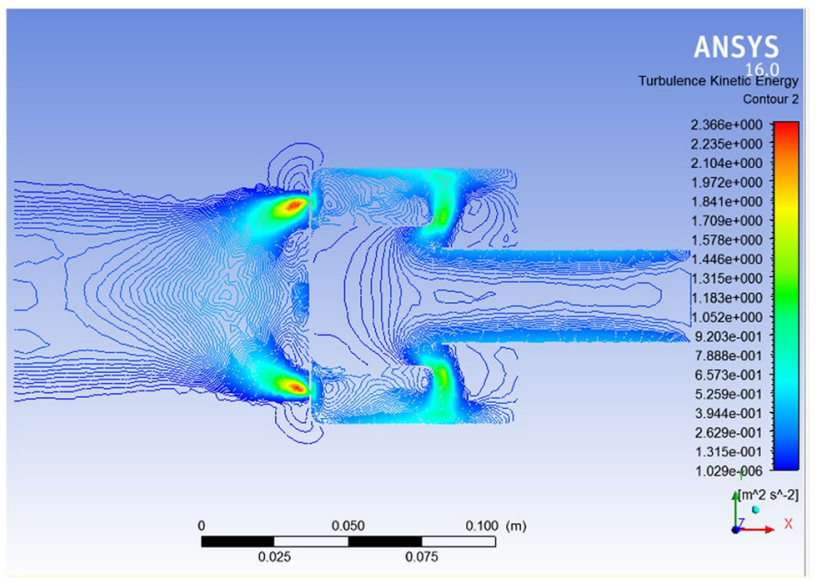

Fig. 9 Turbulent kinetic energy of existing muffler 


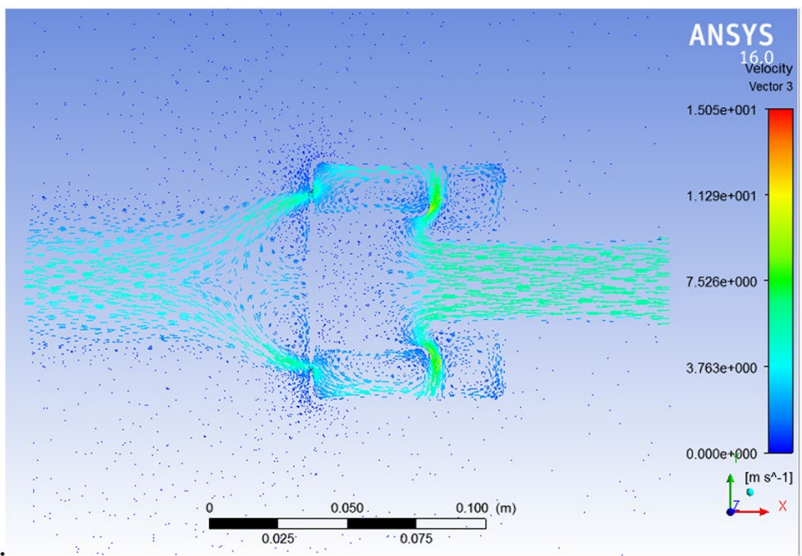

Fig. 10 Velocity vectors of existing muffler

\subsection{New developed model}

Figure 11 shows that the result of acoustic pressure levels for a new developed muffler. It is observed that maximum acoustic pressure level is reduced as compared to the existing model. It is clearly noticed that the acoustic pressure level at outlet of the new developed model is much lesser than the existing model. Therefore, it has been seen that the results of new developed model give better performance as compared to the existing model. But there is sharp variation of colors so a small change in pressure where we can deduce that the resonance phenomena does not appear as shown in Fig. 11.

Figure 12 and 13 shows the turbulent kinetic energy and velocity vectors of new developed muffler and its results. The distribution of the velocity is homogeneous inside the muffler. Therefore, actual gas flow cannot be considered as mean flow. In Fig. 12 Plot also shows that, velocity direction of the flow along with magnitude of the velocity, where, it is noticed that turbulent kinetic energy has been reduced causing reduction in pressure drop.

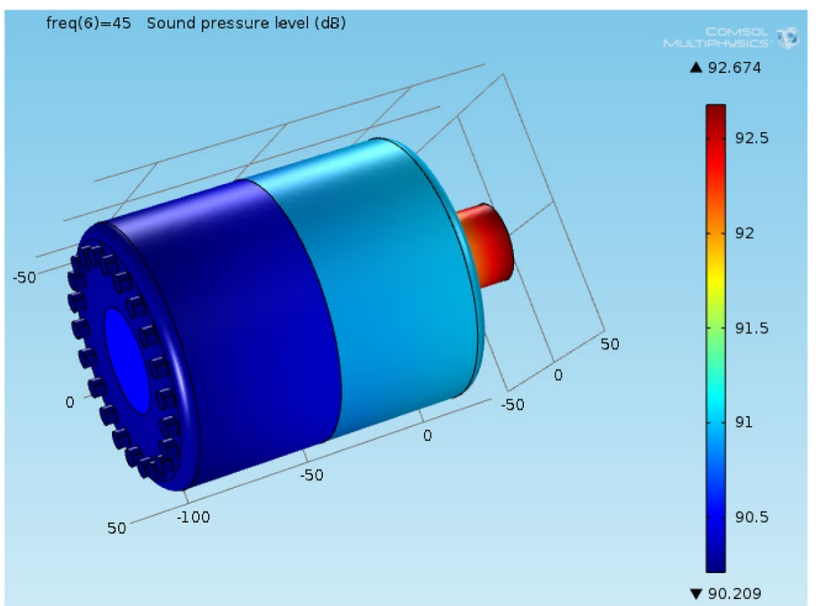

Fig. 11 Acoustic pressure level of new developed muffler
Fig. 12 Turbulent kinetic energy of new developed muffler

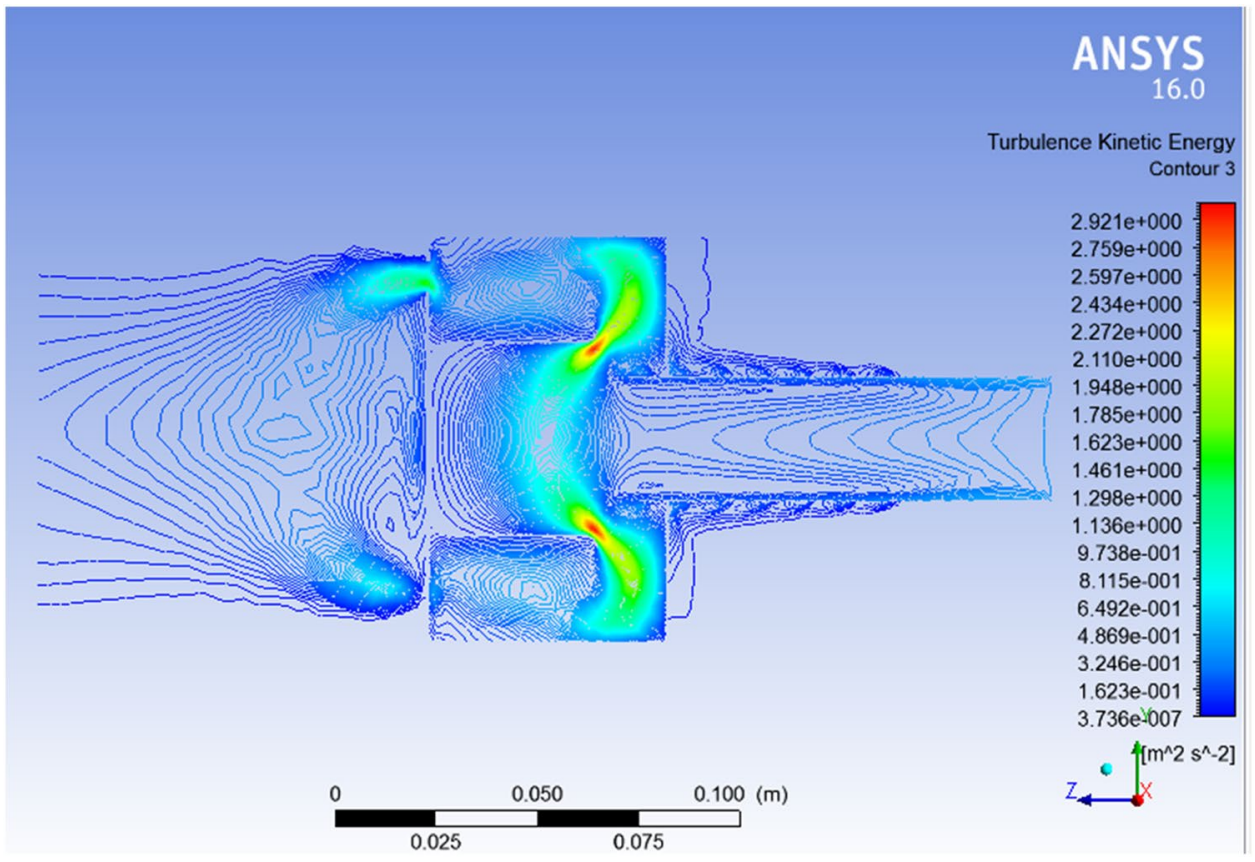


Fig. 13 Velocity vectors of new developed muffler

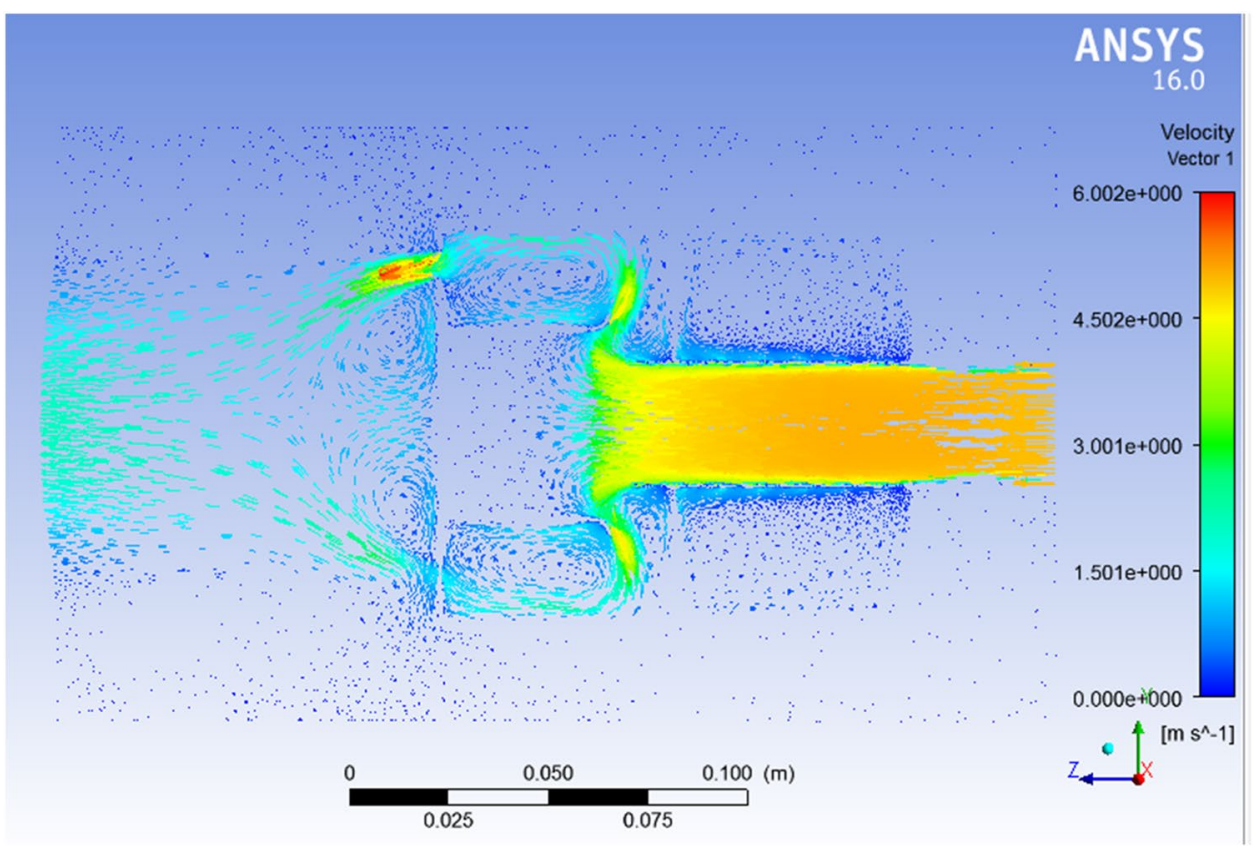

\subsection{Transmission loss}

The transmission loss using experimental and numerical method for existing and new developed mufflers has been discussed in Figs. 14 and 15 respectively. It is noticed that experimental results show three attenuation picks which occurs approximately between 0 and $100 \mathrm{~Hz}$ as shown in Fig. 14. These peaks are of the cup geometry within the existing muffler and a good agreement between the numerical results and experimental measured data is observed. The small variations between these two results may be because of flow noise which was not considered in the simulation.

Figure 15 shows the transmission loss of new developed muffler using the numerical approach and experimental measurements. It has been noticed that the transmission loss is maximum at design frequency of $45 \mathrm{~Hz}$ rather than, the existing muffler at $45 \mathrm{~Hz}$ frequency. It is observed that experimental results show two attenuation picks which occurs approximately between 20 and $60 \mathrm{~Hz}$. These peaks are of the two expansion chambers within the new developed muffler. It has been seen that experimental and numerical results are in good agreement. The small variations between these two results may be due to geometrical differences between the CAD model and the existing muffler. From Figs. 14 and 15, it is to be noted that the mufflers are designed for only low frequencies $(30-50 \mathrm{~Hz})$ when the operating range of the engine is below $50 \mathrm{~Hz}$.

Figure 16 shows the back pressure on engine, using new developed muffler and existing muffler. It can be seen that, there is variation of back pressure with speed while using both mufflers. It is noticed that back pressure

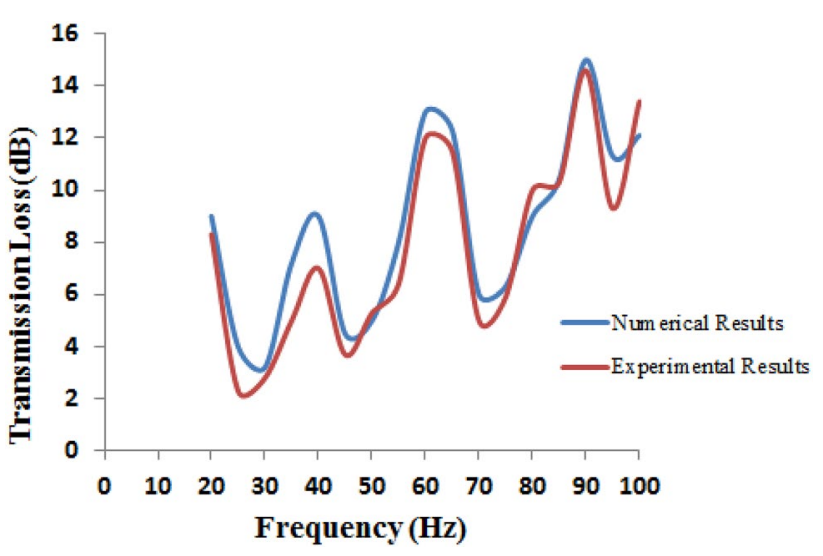

Fig. 14 Transmission loss of the existing muffler

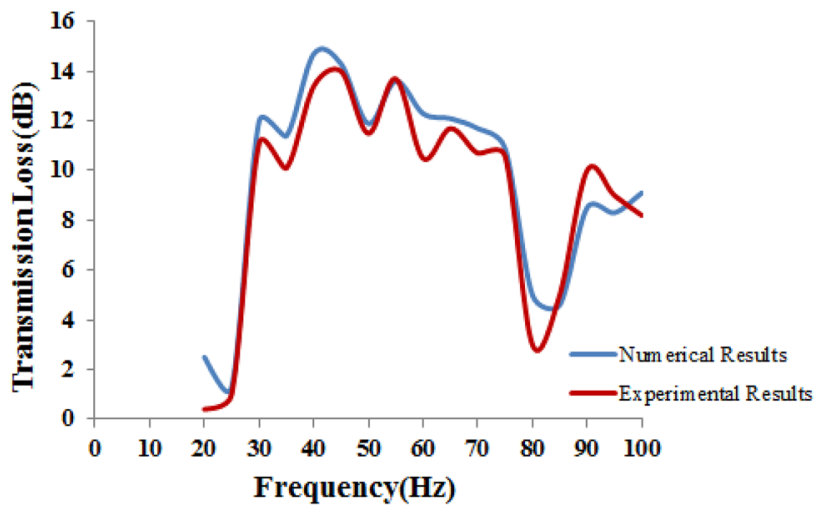

Fig. 15 Transmission loss of the new developed muffler 


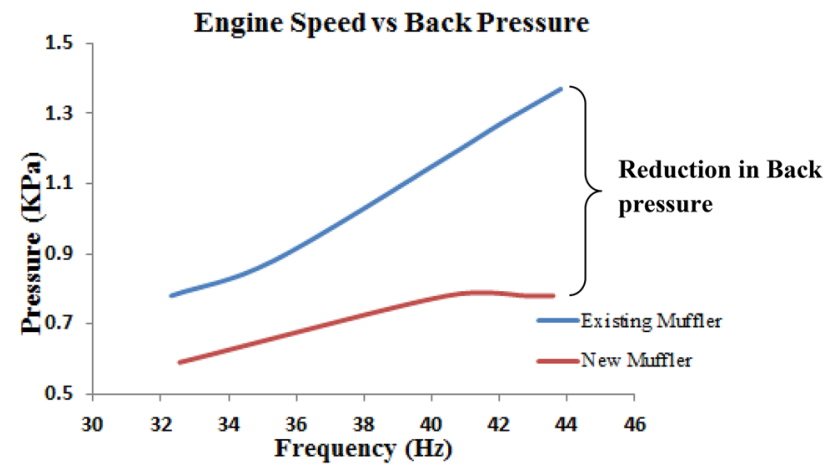

Fig. 16 Engine speed versus back pressure

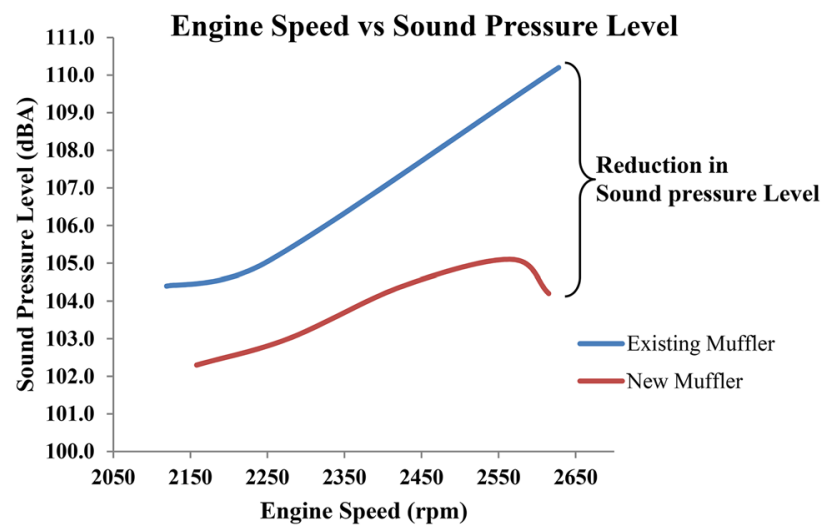

Fig. 17 Engine speed versus sound pressure level

obtained using new developed muffler never intersects the back-pressure data obtained using existing muffler. Overall, it is observed that, the back pressure obtained using new developed muffler is always less than that of the existing muffler irrespective of the speed of the engine. It is also noticed that new developed muffler shows a $42 \%$ reduction in back pressure at $2600 \mathrm{rpm}$.

Figure 17 shows comparison of the results obtained using existing and new developed muffler. It has been seen that up to $2560 \mathrm{rpm}$ both these graphs have similar kind of nature. Also, it is seen that for new developed muffler, sound pressure level starts decreasing at $2560 \mathrm{rpm}$. It is noticed that the sound pressure level decreases up to $104.2 \mathrm{~dB}$ at $2600 \mathrm{rpm}$ as shown in the Table 2 . It is observed that at the same speed existing muffler showed $110.2 \mathrm{~dB}$.

From the Table 2, it's clear from experimental result, that there is $5.5 \%$ reduction in sound pressure level while using new developed muffler as compared to existing muffler. Even specific fuel consumption of engine is reduced significantly by application of new muffler.

Table 2 Comparison of results for existing muffler and new muffler

\begin{tabular}{lcc}
\hline Parameters & Existing muffler & New muffler \\
\hline Sound pressure level $(\mathrm{dB})$ & 110.2 & 104.2 \\
Back pressure/pressure drop $(\mathrm{KPa})$ & 1.37 & 0.78 \\
Specific fuel consumption $(\mathrm{Kg} / \mathrm{kwh})$ & 0.300 & 0.294 \\
\hline
\end{tabular}

\section{Discussion}

Muffler is used to dampen the vibrations and velocity of the exhaust gases resulting in reduction of amount of noise generated by engines. The muffler used to reduce the exhaust noise of diesel engines. With this relevance, the study investigates the new developed and the existing muffler.

In this paper, study is carried out to examine transmission loss, acoustic pressure levels and flow characteristics of muffler. The comparison of result obtained are reported in Table 2. The experimental results on reduction in noise level, specific fuel consumption, back pressure and transmission loss are compared with experimental published results $[26,27]$. The result presented in a literature $[26,27]$ are for $16 \mathrm{hp}$ diesel engine with muffler size of $750 \times 200 \mathrm{~mm}$. The results presented in this manuscript are for $4 \mathrm{hp}$ diesel engine with muffler size of $150 \times 100 \mathrm{~mm}$. With comparison of result presented in literature, the specific fuel consumption, back pressure and transmission loss is improved. The reduction in noise level in literature is $14 \mathrm{~dB}$ whereas obtained noise level by using new muffler $6 \mathrm{~dB}$. The comparison is shown in Table 3.

Table 3 Comparison of experimental results presented in the literature

\begin{tabular}{llll}
\hline Sr No. & Parameter & $\begin{array}{l}\text { Results for literature }[26,27] \text { (16 Hp diesel } \\
\text { engine with } 750 \times 200 \text { mm muffler size) }\end{array}$ & $\begin{array}{l}\text { Results presented (4 Hp diesel } \\
\text { engine with 150 } \times 100 \text { mm muffler } \\
\text { size) }\end{array}$ \\
\hline 1 & Specific fuel consumption $(\mathrm{Kg} / \mathrm{kwh})$ & 0.33 & 0.294 \\
2 & Back pressure/pressure drop (Kpa) & 1.96 & 0.78 \\
3 & Sound pressure level (dB) & 14 & 6 \\
4 & Transmission loss (dB) & 13 & 14 \\
\hline
\end{tabular}


Further improvement in muffler can be made possible by inculcating absorptive materials, perforated plates, baffle plates etc. authors are currently working on same issues.

\section{Conclusions}

Based on the experimental and numerical analysis, major findings are summarized below:

(1) The numerical results and experimental results demonstrate that, new muffler shows maximum transmission loss approximately $14 \mathrm{~dB}$ by using new muffler.

(2) Noise is reduced by $5.5 \%$ by using new muffler by increasing volume to $0.0004 \mathrm{~m}^{3}$ as compared to that of existing muffler, by using perforated pipe with 15\% porosity along with single perforated baffle plate using pressure acoustic approach.

(3) It is also seen that new developed muffler can be successfully used for 4 HP diesel engine, which significantly reduces back pressure by $42 \%$.

(4) Evaluation of the performance characteristics for 4 $\mathrm{hp}$ diesel engine in relation to back pressure, acoustic attenuation and speed shows good agreement with standard nature of the graph.

Acknowledgements The authors wish to thank the Rocket Engineering Corporation Pvt. Ltd. Kolhapur, Engine Division Technical Center for their technical support and helpful discussions.

\section{Compliance with ethical standards}

Conflict of interest Conflict of interest on behalf of all authors, the corresponding author states that there is no conflict of interest.

\section{References}

1. BB Ghosh, J Chaudhury, TK Banerjee, AK Ghosh (1999) Development of a muffler for control of noise pollution in a diesel engine. In: Proceedings of Institution of Mechanical Engineers, vol 213 Part D, pp 83-90

2. Munjal ML (1987) Acoustic of ducts and mufflers, vol 2. Wiley, New York

3. Liu C, Ji Z (2014) Computational fluid dynamics-based numerical analysis of acoustic attenuation and flow resistance characteristics of perforated tube silencers. ASME J Vib Acoust 136:021006-1-21011

4. Shah S, Saisankaranarayane K, Kalyankumar S, Thombare DG (2010) A practical approach towards muffler design, development and prototype validation. SAE Int 032-0021:1-16

5. Mogal SP, Behera RK, Pawar SY (2011) Design and development of muffler for diesel generator set for reduction of noise. Int J Eng Sci Technol 3(4):3591-3595
6. Middelberg JM, Barber TJ, Leong SS, Byrne KP, Leonardi E (2004) CFD analysis of the acoustic and mean flow performance of simple expansion chamber mufflers. In: ASME paper no. IMECE2004-61371

7. Parlar Z, Ari S, Yilmaz R, Özdemir E, Arda K (2013) Acoustic and flow field analysis of a perforated muffler. World Acad Sci Eng Technol 7(3):447-451

8. Potente D (2005) General design principles for an automotive muffler. In: Proceedings of acoustics, Busselton, Australian Acoustical Society, pp 153-158

9. Ying-li S, Pei W, Ying-li S (2010) A study on exhaust muffler with low backpressure. In: IEEE, pp 7739-5/10

10. Om AriaraGuhana CP, Arthanareeswarana G, Varadarajanb KN, Krishnanc S (2018) Exhaust system muffler volume optimization of light commercial vehicle using CFD simulation. Elsevier Mater Today Proc 5:8471-8479

11. Jong KL, KeeSeung O, Jin WL (2019) Methods for evaluating induct noise attenuation performance in a muffler design problem. Elsevier J Sound Vib 464:114982

12. Selamet A, Dickey NS, Novak JM (1995) A time-domain computational simulation of acoustic silencers. ASMEJ Vib Acoust 117:323-331

13. Broatch A, Margot X, Gil A (2005) A CFD approach to the computation of the acoustic response of exhaust mufflers. J Comput Acoust 13(2):301-316

14. Lee SH, Ih JG (2008) Effect of non-uniform perforation in the long concentric resonator on transmission loss and back pressure. J Sound Vib 311:280-296

15. Lee SH, Ih JG (2003) Empirical model of the acoustic impedance of a circular orifice in grazing mean flow. J Acoust Soc Am 114(1):98-113

16. Xue F, Sun B (2018) Experimental study on the comprehensive performance of the application of U-shaped corrugated pipes into reactive mufflers. Elsevier Appl Acoust 141:362-370

17. Jianbing G, Chaochen M, Shikai X, Liwei S, Jiangquan L (2016) Polycyclic aromatic hydrocarbon emissions of non-road diesel engine treated with non-thermal plasma technology. Korean J Chem Eng 33:3425-3433

18. Gao J, Ma C, Tian G, Chen J, Xing S, Huang L (2018) Oxidation activity restoration of diesel particulate matter by aging in air. Energy Fuels 32:2450-2457

19. Gao J, Chen H, Tian G, Ma C, Zhu F (2019) An analysis of energy flow in a turbocharged diesel engine of a heavy truck and potentials of improving fuel economy and reducing exhaust emissions. Elsevier Energy Convers Manag 184:456-465

20. Yaqiang $X$, Guoyong J, Tiangui $Y$, Kangkang S, Saifeng Z, Chuanmeng $Y$ (2020) Isogeometric analysis for geometric modelling and acoustic attenuation performances of reactive mufflers. Comput Math Appl. https://doi.org/10.1016/j.camwa .2020.02.004

21. Adrien M, Min-Suk K, Barbara N, Franck P, Robert P (2015) Exhaust and muffler aeroacoustics predictions using lattice Boltzmann method. SAE Int J Passeng Cars Mech Syst 8(3):1009-1117

22. Usama T, Chris G, John K, Ilaria A, Arturo P-V (2014) Parametric analysis of a pulsco vent silencer. In: Proceedings of the ASME 2014 international mechanical engineering congress and exposition (IMECE2014), 1-10

23. Azevedo FM, Moura MS, Vicente WM, Picelli R, Pavanello R (2012) Topology optimization of reactive acoustic mufflers using a bidirectional evolutionary optimization method. Springer Struct Multidiscip Optim 58:2239-2252

24. Yedeg EL, Wadbro E, Berggren M (2016) Interior layout topology optimization of a reactive muffler. Springer Struct Multidiscip Optim 53:645-656 
25. Zhang Y, Pei Wu, Ma Y, He Su, Xue J (2018) Analysis on acoustic performance and flow field in the split-stream rushing muffler unit. Elsevier J Sound Vib 430:185-195

26. Bhattacharya P, Ghosh BB, Bose PK (2010) Transmission loss and performance test of a two cylinder four stroke diesel engine. J Eng Sci Technol 5(3):284-292

27. Bhattacharya P, Panua R, Bose PK, Ghosh BB (2008) Design of reactive muffler for study on the noise level and performance of a two-cylinder four stroke 16 h.p. diesel engine. Noise Vib Worldwide 39(8):24-27
28. Shinde PV, Gavali PM, Barawade RA, Mohite YB, Shinde PB (2017) A review on muffler design for exhaust noise attenuation. Int J Eng Technol (IJET) 9(3S):428-431

29. Fluent (2006) Fluent6.3 User's Guide, Fluent Inc., New York

Publisher's Note Springer Nature remains neutral with regard to jurisdictional claims in published maps and institutional affiliations. 